\title{
Destinasi Wisata Kolong Bekas Tambang: Analisis Pengembangan dan Konvektivitas Wisata
}

\author{
Novalia Ega Saputri*, Gina Puspitasari Rochman \\ Prodi Perencanaan Wilayah dan Kota, Fakultas Teknik, Universitas Islam \\ Bandung, Indonesia. \\ *novalia0898@gmail.com, gina.puspitasari@unisba.ac.id
}

\begin{abstract}
Terong Village, in Belitung Regency's Sijuk District, has potential to enhance tourism activities. The development of the Aik Rusa' Berehun tourist attraction, which exploits previously abandoned tin mine land to become a unique tourist destination with increased potential value, is one of Terong Village's possible uses. The Aik Rusa' Berehun community group, as well as the local community of Terong Village, collaborated on the establishment of this attraction. The purpose of this study is to determine the growth of tourism components such as Attraction, Amenity, Accessibility, and Ancilliary, or the 4A component, in the tourist destination of Aik Rusa' Berehun, as well as its linkage with pre-existing tourist sites. Observations and identification of the deficiency were carried out in this research. Observations and identification of the Aik Rusa' Berehun Tourism Destination's development conditions were carried out in this study based on field observations. This study was supported by a qualitative technique based on exploratory research. Observation, interviews, and documentation are used to obtain primary data. Purposive sampling was employed in conjunction with in-depth interviews with key informants, such as stakeholders. Literature studies utilize secondary data collection approaches. Descriptive analysis was used to conduct the investigation. Data compilation, data reduction, and the creation of study outcomes narratives are all examples of data processing. The development of Aik Rusa' Berehun Tourism Destinations is positive, as evidenced by the available 4A components that can be used to properly support tourist activities so that visitors can feel safe and comfortable while enjoying existing tourist attractions, though some aspects still require improvement. The Aik Rusa' Berehun tourist destination, based on its proximity to other tourist sites, has emerged as a new tourist destination in Terong Village, as well as a supporting tourist destination for nearby tourist locations.
\end{abstract}

Keywords: Tourism, Identification of 4A Components, Void Ex-Mining, Connectivity of Tourist Destinations

\begin{abstract}
Abstrak. Desa Terong terletak di Kecamatan Sijuk, Kabupaten Belitung memiliki potensi-potensi yang dapat dikembangkan untuk mendukung kegiatan pariwisata. Salah satu pemanfaatan potensi Desa Terong yaitu melalui pengembangan destinasi wisata Aik Rusa' Berehun yang memanfaatkan kolong bekas tambang timah yang sebelumnya terbengkalai menjadi destinasi wisata yang unik dan lebih memiliki nilai potensial. Pengembangan destinasi ini dilakukan dengan melibatkan kelompok masyarakat Aik Rusa' Berehun dan juga mengikutsertakan masyarakat lokal Desa Terong. Penelitian ini bertujuan untuk mengidentifikasi pengembangan komponen wisata yang terdiri dari Attraction, Amenity, Accessibility, Ancilliary atau biasa disingkat menjadi komponen 4A di destinasi wisata Aik Rusa' Berehun serta konektivitasnya dengan destinasi wisata sekitar yang sudah ada sebelumnya. Dalam penelitian ini dilakukan pengamatan dan identifikasi mengenai kondisi pengembangan Destinasi Wisata Aik Rusa' Berehun berdasarkan hasil pengamatan di lapangan. Untuk mendukung penelitian ini digunakan metode pendekatan kualitatif menggunakan jenis penelitian exploratif (Exploratory Research). Pengumpulan data primer dilakukan dengan observasi (pengamatan), interview (wawancara), dan dokumentasi. Teknik sampling menggunakan purposive sampling yaitu dilakukan wawancara mendalam kepada informan kunci yaitu para pemegang kepentingan. Teknik pengumpulan data sekunder dilakukan dengan studi literatur. Analisis dilakukan dengan analisis deskriptif. Pengolahan data dilakukan dalam bentuk kompilasi data, reduksi data, dan penyusunan narasi hasil penelitian. Perkembangan Destinasi Wisata Aik Rusa' Berehun sudah baik dapat diidentifikasi dari komponen 4A yang tersedia sudah bisa digunakan untuk menunjang kegiatan wisatawan dengan baik sehingga wisatawan yang berkunjung dapat merasa nyaman dan aman serta menikmati objek wisata yang ada meskipun di beberapa aspek masih butuh pembenahan. Dilihat dari konektivitas dengan destinasi wisata lain yang ada di sekitar, destinasi wisata Aik Rusa' Berehun menjadi sebuah destinasi wisata baru di Desa Terong sekaligus berfungsi sebagai destinasi wisata pendukung bagi destinasi wisata sekitar.
\end{abstract}

Kata Kunci: Pariwisata, Identifikasi Komponen 4A, Kolong Bekas Tambang, Konektivitas Destinasi Wisata. 


\section{A. Pendahuluan}

Pembangunan suatu wilayah pada dasarnya bersifat dinamis dan dilaksanakan untuk menghasilkan perubahan yang terus menerus di berbagai bidang dengan bertujuan untuk meningkatkan mutu kehidupan masyarakat. Pariwisata menjadi salah satu prioritas utama untuk menunjang pembangunan wilayah karena dinilai sebagai salah satu sektor yang memiliki prospek yang baik di bidang ekonomi ${ }^{[1]}$. Dalam hal ini pembangunan dan pengembangan di bidang pariwisata juga mengalami perkembangan sekaligus perubahan dalam konteks memanfaatkan sumber daya alam yang bertujuan meningkatkan mutu kehidupan masyarakat. Tujuan pengembangan pariwisata akan berhasil dengan optimal bila ditunjang oleh potensi daerah yang berupa objek wisata baik wisata alam maupun wisata buatan manusia ${ }^{[2]}$. Potensi yang dapat dikembangkan khususnya dalam mendukung pariwisata di kawasan perdesaan adalah berkaitan dengan sumber daya alam dan keindahan alam serta seni dan budaya ${ }^{[3]}$.

Kabupaten Belitung merupakan salah satu wilayah di Pulau Belitung yang terkenal sebagai sabuk timah Asia Tenggara ${ }^{[4]}$. Kegiatan penambangan timah yang dilakukan secara terus-menerus menyisakan suatu masalah yaitu kawasan bekas tambang yang terbengkalai dan ditinggalkan karena dianggap sudah tidak dapat untuk dilakukan penambangan timah di kawasan tersebut. Kawasan tersebut biasa disebut oleh masyarakat dengan nama "kolong". Kolong dalam definisinya dapat disebut sebagai lubang bekas tambang yang berbentuk seperti danau, berisi air dan memiliki kedalaman rata-rata 4-5 meter, tetapi ada yang mencapai hingga 40 meter ${ }^{[5]}$. Kolong bekas tambang yang terbengkalai ini telah mengurangi nilai estetika maupun kelestarian lingkungan sekitar, serta sangat kurang jika dilihat dari kebermanfaatannya. Dari hasil beberapa survey yang telah dilakukan pemanfaatan kolong oleh masyarakat di Bangka Belitung adalah pemanfaatan kolong untuk perikanan, mandi dan mencuci, air minum, dan rekreasi ${ }^{[6]}$.

Kabupaten Belitung merupakan salah satu wilayah yang termasuk dalam program pemerintah pusat yaitu berdasarkan Peraturan Pemerintah Republik Indonesia Nomor 50 Tahun 2011 Tentang Rencana Induk Pembangunan Kepariwisataan Nasional Tahun 2010-2025, ditetapkan Kawasan Strategis Pariwisata Nasional (KSPN) di Kabupaten Belitung yaitu KSPN Tanjung Kelayang dan sekitarnya. Hal ini dikarenakan Kabupaten Belitung memiliki potensi alam yang baik dengan salah satu kekhasannya adalah di bidang pariwisata khususnya wisata bahari. Selain terkenal dengan wisata bahari, adanya lahan bekas penambangan yang membentuk kolong dan tersebar di beberapa wilayah di Kabupaten Belitung disadari oleh pemerintah daerah sebagai suatu potensi agar lahan-lahan galian bekas tambang tersebut dapat dimanfaatkan menjadi suatu komoditas yang memiliki nilai jual yang tinggi.

Mengingat sifat sektor pariwisata yang relatif ramah lingkungan dan bersifat multi sektoral, maka Pemerintah Daerah Kabupaten Belitung mulai mempertimbangkan berbagai alternatif pengembangan kawasan bekas pertambangan salah satunya dengan mengembangkan kawasan bekas pertambangan menjadi objek wisata. Hal ini bertujuan untuk mempertahankan kelestarian lingkungan dan meningkatkan nilai ekonomi dari kawasan bekas pertambangan yang sudah ada sebelumnya. Pemanfaatan kolong bekas tambang menjadi sebuah destinasi wisata dilakukan pada wilayah di Kabupaten Belitung yaitu salah satunya di Desa Terong yang berada di daerah pesisir pantai utara Kecamatan Sijuk, Kabupaten Belitung. Melalui ditetapkannya KSPN Tanjung Kelayang dan sekitarnya, Desa Terong termasuk ke dalam wilayah sekitar dari Tanjung Kelayang dengan berjarak $\pm 13,5 \mathrm{~km}$ dan memiliki daya tarik wisata adat dan tradisi. Kemudian dalam Geopark Belitong, Desa Terong merupakan salah satu Geosite dengan potensi wisata yaitu adanya kolaborasi beberapa komunitas dalam mengembangkan destinasi wisata di dalam Desa tersebut.

Salah satu pengembangan pariwisata yang dilakukan di Desa Terong adalah kolong bekas tambang timah yang sebelumnya merupakan sumber ancaman bagi masyarakat kemudian diubah untuk dimaksimalkan potensinya bagi pengembangan Desa Terong dengan dikembangkan menjadi destinasi wisata baru yaitu Destinasi Wisata Aik Rusa' Berehun. Destinasi wisata ini telah beroperasi dengan menawarkan produk lokal sehingga bernilai tinggi dan dapat menarik minat wisatawan. Dalam mengembangkan sebuah destinasi wisata perlu diperhatikan empat komponen utama sebuah destinasi wisata yaitu Attraction, Amenity, 
Accessibility, Ancilliary. Keempat komponen utama tersebut dapat disingkat menjadi komponen penunjang wisata 4A. Destinasi wisata Aik Rusa' Berehun dalam mengembangkan 4A tersebut dikelola oleh Kelompok Aik Rusa' Berehun dengan tetap terintegrasi dengan Badan Permuyawaratan Desa bersama Pemerintah Desa Terong. Kelompok Aik Rusa' Berehun telah berhasil mengubah kolong bekas tambang timah menjadi lebih memiliki nilai potensial bagi Desa Terong maupun masyarakat Desa Terong itu sendiri.

Sehingga perlu dilakukan penelitian untuk mengidentifikasi bagaimana pengembangan destinasi wisata kolong bekas tambang di Desa Terong yang dilakukan oleh kelompok Kelompok Aik Rusa' Berehun dengan melihat dari segi pengembangan komponen 4A (Attraction, Amenity, Accessibility, Ancilliary) guna memeuhi kebutuhan pengunjung wisata. Serta mengidentifikasi kedudukan Destinasi wisata Aik Rusa' Berehun sebagai sebuah destinasi wisata baru dengan melihat dari konektivitasnya dengan destinasi wisata yang sudah ada di sekitar Desa Terong.

Berdasarkan latar belakang yang telah dijelaskan, maka rumusan masalah dalam penelitian ini adalah sebagai berikut: "Bagaimana bentuk pengembangan komponen wisata 4A di destinasi wisata Aik Rusa' Berehun serta konektivitasnya dengan destinasi wisata sekitar?". Selanjutnya, tujuan dalam penelitian ini yaitu mengidentifikasi pengembangan komponen wisata 4A di destinasi wisata Aik Rusa' Berehun serta konektivitasnya dengan destinasi wisata sekitar yang sudah ada sebelumnya.

\section{B. Metodologi Penelitian}

Penelitian ini dilakukan di Destinasi Wisata Aik Rusa' Berehun yang terletak di Desa Terong, Kecamatan Sijuk, Kabupaten Belitung. Metode pendekatan penelitian yang digunakan yaitu pendekatan kualitatif, pendekatan ini memiliki proses penelitian yang menghasilkan data deskriptif seperti catatan verbal serta perilaku dari objekyang diamati, setelah itu kemudian dilanjutkan dengan menemukan maknanya ${ }^{[7]}$. Jenis penelitian yang digunakan yaitu jenis penelitian exploratif (Exploratory Research) karena dimaksudkan untuk menjelaskan objek penelitian berdasarkan fakta dan data yang sebenarnya ${ }^{[8]}$.

Data yang digunakan dalam penelitian ini yaitu berupa data primer dan data sekunder. Teknik pengumpulan data primer dilakukan dengan observasi (pengamatan), interview (wawancara), dan dokumentasi. Dalam melakukan observasi peneliti menggunakan observasi terbuka karena dalam melakukan pengumpulan data peneliti menyatakan sebenarnya kepada sumber data bahwa sedang melakukan penelitian. Objek yang di observasi adalah terkait kondisi di Destinasi Wisata Aik Rusa' Berehun. Data-data mengenai objek penelitian yang tidak diperoleh selama observasi langsung di lokasi penelitian dilakukan pendalaman dengan wawancara agar infomasi menjadi lebih lengkap.

Teknik sampling menggunakan purposive sampling yaitu dilakukan wawancara mendalam kepada informan kunci yaitu Kepala Desa Terong, Ketua PIC Desa Terong, dan Kelompok Masyarakat Aik Rusa' Berehun. Menurut Sugiyono (2015), purposive sampling merupakan pengambilan sumber data dengan pertimbangan tertentu, seperti orang yang dianggap tahu tentang apa yang diharapkan ${ }^{[9]}$. Metode dokumentasi dalam penelitian ini dilakukan untuk memperoleh data dengan cara dokumentasi pengambilan gambar di Destinasi Wisata Aik Rusa' Berehun, Desa Terong. Teknik pengumpulan data sekunder dilakukan dengan survey instansional dan studi literatur yang bersumber dari artikel di internet, jurnal, buku atau situs yang terkait dengan penelitian yang dilakukan.

Data yang didapatkan kemudian diolah dengan membuat tabulasi data, memilah atau mereduksi data-data yang berkaitan dengan topik penelitian, dan menyusun deskripsi hasil penelitian ${ }^{[10]}$. Dalam penelitian ini dilakukan analisis data kualitatif menggunakan versi Miles dan Huberman. Menurut Sugiyono (2013), kegiatan analisis data kualitatif dilakukan dengan bersifat interaktif, terus-meneurs dan berkesinambungan hingga datanya jenuh ${ }^{[11]}$. Dalam analisis ini dilakukan reduksi data (data reduction), penyajian data (data display) dan penarikan kesimpulan (verification). Teknik triangulasi yang dilakukan yaitu menggunakan teknik triangulasi teknik karena penulis mengumpulkan data dengan teknik yang beragam untuk mengambil data dari sumber data yang sama. Penyajian hasil penelitian ini dijabarkan secara 
deskriptif dengan tujuan mendeskripsikan fenomena atau kejadian yang terjadi dan berlangsung di lapangan. Dalam analisis deskriptif dilakukan dengan menganalisis, menggambarkan, dan merangkum kondisi-kondisi yang berbeda dari berbagai data yang dikumpulkan dalam bentuk wawancara atau observasi mengenai masalah yang diteliti di lapangan.

\section{Hasil dan Pembahasan}

\section{Analisis dan Pembahasan Komponen 4A Destinasi Wisata Aik Rusa' Berehun}

Sugiama (2014) mengatakan bahwa di dalam suatu destinasi wisata harus ditunjang oleh adanya ketersediaan komponen kepariwisataan. Komponen kepariwisataan tersebut adalah 4A yaitu Attraction, Amenities, Accesibility, dan Ancilliary ${ }^{[13]}$. Destinasi Wisata Aik Rusa' Berehun termasuk ke dalam destinasi wisata baru di Desa Terong yang mulai dilakukan sejak tahun 2016 lalu. Sehingga destinasi wisata ini beserta komponen wisata di dalamnya pada dasarnya masih terus berkembang hingga saat ini. Adapun identifikasi mengenai komponen 4A Destinasi Wisata Aik Rusa' Berehun akan dijabarkan sebagai berikut.

1. Identifikasi Attraction (Atraksi Wisata) Destinasi Wisata Aik Rusa' Berehun Adanya kunjungan wisatawan berkaitan dengan pengembangan atraksi wisata/daya tarik wisata. Yoeti (2006) menyatakan bahwa daya tarik wisata inilah yang menjadi motivasi dan daya tarik yang melatarbelakangi wisatawan untuk mengunjungi suatu daerah tertentu ${ }^{[14]}$. Terdapat tiga persyaratan yang harus dipenuhi oleh objek daya tarik wisata yaitu Something to see (sesuatu yang dapat dilihat), Something to do (sesuatu yang dapat dikerjakan), dan Something to buy (sesuatu yang dapat dibeli/suvenir) ${ }^{[15]}$. Berbagai atraksi wisata menarik disajikan di Destinasi Wisata Aik Rusa' Berehun agar memberikan kesan kepada wisatawan. Destinasi Aik Rusa' Berehun memiliki beberapa atraksi wisata yang termasuk ke dalam paketpaket wisata, diantaranya adalah sebagai berikut:

\section{- Makan Bedulang}

Makan Bedulang merupakan tata cara makan adat Belitung yang mengandung beberapa filosofi tentang saling menghargai, menghormati dan menyayangi antara orang tua dan orang muda. Di dalam satu dulang yang terdiri dari beberapa menu masakan khas Belitung ini yang disajikan khusus untuk empat orang. Dalam penyajiannya wadah dulang ditutup dengan tudung saji yang terbuat dari anyaman daun lais, dalam filosofinya yang pertama membuka tutup tudung saji tersebut adalah orang yang umurnya paling muda di antara 4 (empat) orang yang duduk saling berhadapan mengelilingi dulang. Kemudian orang yang paling muda tersebut mengambilkan piring makanan dan mengambil nasi kemudian diberikan satu persatu secara berurutan dimulai kepada orang yang paling tua umurnya sampai kemudian orang yang paling muda tersebut mengambil nasi untuk piringnya sendiri. Hal inilah yang menggambarkan filosofi makan bedulang secara umum yang mengandung makna bahwa orang muda wajib menghormati orang yang paling tua umurnya, orang yang paling tua umurnya pun wajib menyayangi orang muda dengan mengayomi dan selalu memberikan contoh tauladan yang baik dengan selalu bersikap adil.
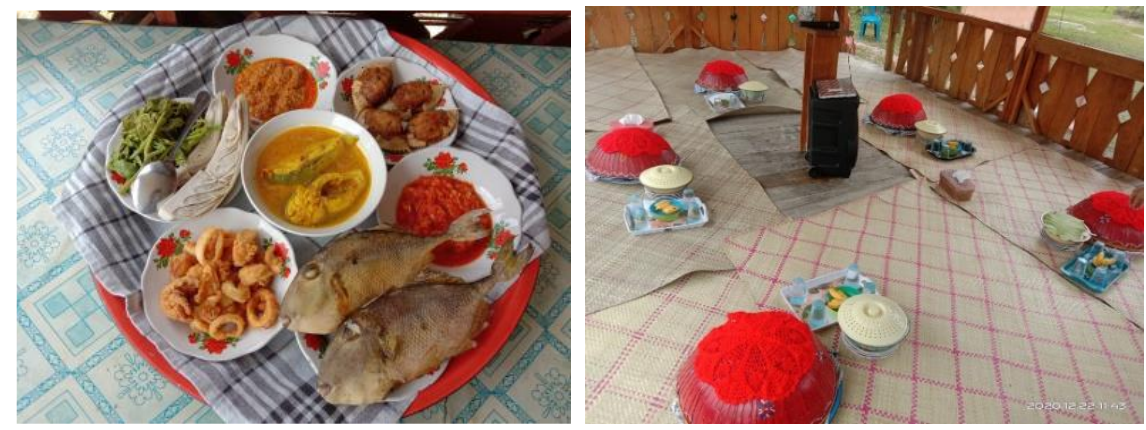

Gambar 1. Makan Bedulang 
- Kuliner

Melalui wisata edukasi belajar memasak makanan kuliner khas Belitung yang diajarkan memasak serta filosofi cara meramu rempah-rempah asli Belitung khusunya rempah-rempah lokal asli Desa Terong yang mengandung berbagai khasiat obat-obatan herbal yang sangat bermanfaat untuk kesehatan tubuh manusia. Atraksi wisata ini sangat unik dan interaktif, bahkan mengandung filosofi yang sangat dalam tentang kehidupan saling menghargai dan menghormati antar sesama manusia

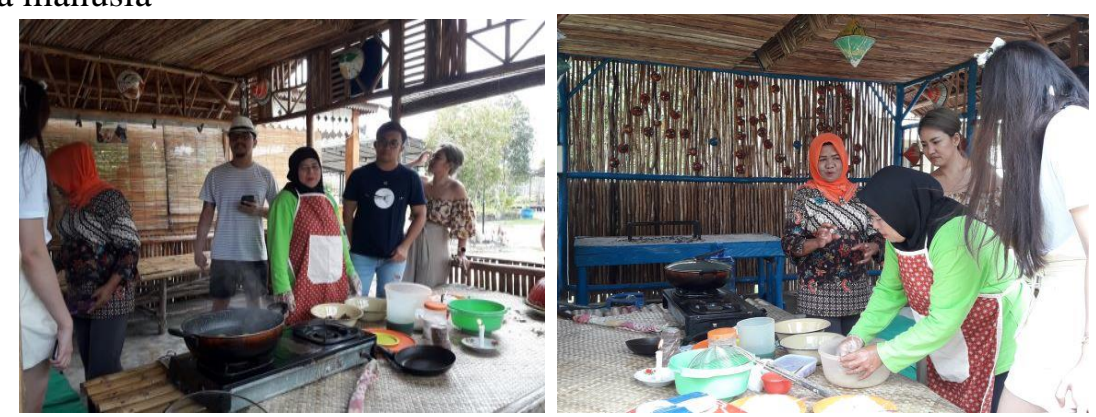

Gambar 2. Atraksi Wisata Kuliner

- Seni Tari Lokal, Seni Musik Gambus dan Seni Gendang Haderah

Kesenian dan kebudayaan lokal menjadi suatu atraksi wisata. Dalam menjaga kelestarian seni dan budaya diperlukan upaya yang berkesinambungan dengan berbagai cara yang kreatif serta edukatif. Upaya yang kreatif dilakukan agar dalam proses pelestarian budaya dapat berjalan secara dinamis khususnya ditujukan kepada generasi muda saat ini. Upaya yang edukatif dilakukan agar dalam proses pelestarian serta pengenalan seni dan budaya pada generasi muda tersebut dapat menimbulkan kesan rasa memiliki dan kecintaan pada adat, seni dan budaya asli Indonesia. Sehingga diharapkan kemudian dapat selalu menurunkan warisan budaya tersebut pada generasi-generasi berikutnya. Salah satu upaya kreatif dan edukatif dalam menjaga kelestarian dan pengenalan seni budaya pada generasi muda yang dilakukan di Desa Terong adalah dengan melakukan edukasi tari kepada wisatawan di Sanggar Tari Aik Rusa' Berehun dan musik yang diiringi oleh Orkes Gambus "Ombak Berayun".

Musik Gambus adalah satu musik yang bercirikan adat Melayu Belitung, walaupun sebenarnya dalam musik Gambus Belitung terdapat pengaruh dari Gambus Melayu Kalimantan. Sehingga terdapat kolaborasi etnik Melayu Belitung dan Melayu Kalimantan. Sebagai bagian dari seni dan budaya yang harus dilestarikan di Desa Terong, musik Gambus selalu diperkenalkan kepada wisatawan lewat penawaran Paket Wisata yang dikemas menjadi bagian dari atraksi wisata yang unik dan menarik.

Seni Haderah adalah bagian dari seni musik etnis Arab Melayu Belitung yang hanya menggunakan gendang sebanyak 3 (tiga) buah gendang. Masing-masing gendang 1, 2 dan 3 mempunyai ciri khas pukulan yang berbeda-beda, sehingga saat dipukul bersamaan akan menghasilkan alunan suara musik yang indah dan enak di dengar. Pada zaman dulu biasanya Seni Haderah ini di lakukan atau dipentaskan pada malam acara perayaan pernikahan pengantin adat Belitung. Syair-syair yang dinyanyikan berbahasa Arab dan mengandung pujian-pujian kepada Sang Maha Pencipta. Terasa sekali sentuhan religiusnya, sehingga bagi yang mendengarkannya akan terbawa dalam rasa yang tenang dan tentram dalam kedamaian. 

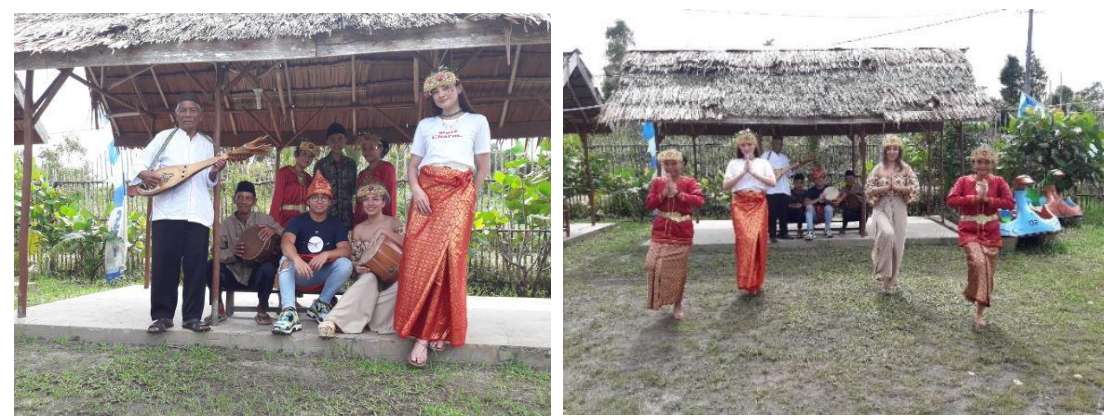

Gambar 3. Atraksi Wisata Seni Tari Lokal dan Seni Musik Gambus

2. Identifikasi Amenities (Amenitas Wisata) Destinasi Wisata Aik Rusa' Berehun

Amenitas dapat berupa kondisi dan ketersediaan fasilitas untuk menunjang pariwisata yang sekaligus menjadi dasar penetapan program pengembangan fasilitas untuk mendukung kemudahan dan kenyamanan wisatawan dalam mengakses pariwisata maupun pelayanan yang ada di dalamnya. Amenitas adalah segala sesuatu yang mendukung destinasi wisata yang sifatnya berupa ketersediaan fasilitas, sarana dan prasarana penunjang wisata sehingga wisatawan merasakan kemudahan dan kenyamanan dalam berwisata.
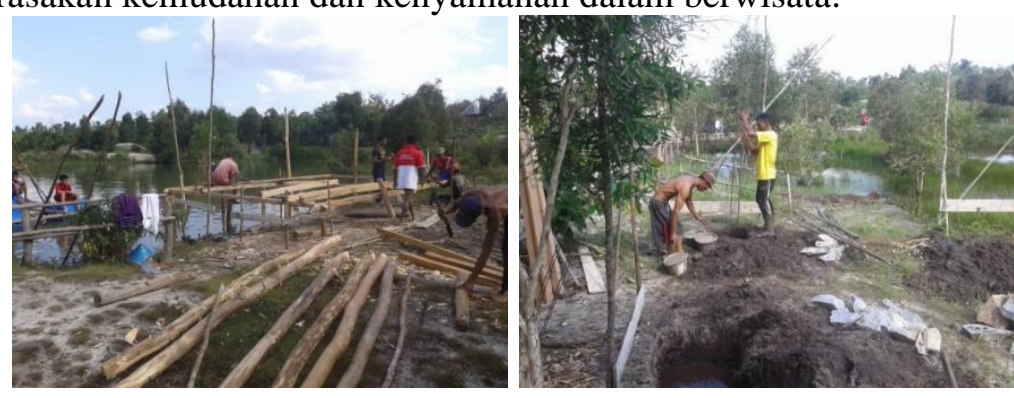

Gambar 4. Partisipasi Masyarakat dalam Pembangunan Fisik Destinasi Wisata Aik Rusa' Berehun

Di dalam destinasi wisata Aik Rusa' Berehun telah dibangun berbagai fasilitas penunjang kegiatan pariwisata. Pembangunan fasilitas-fasilitas tersebut tidak terlepas dari adanya peran dan partisipasi dari masyarakat Desa Terong yang ikut serta dalam pembangunan fisik destinasi wisata ini. Keikutsertaan masyarakat Desa Terong dalam pembangunan fisik Destinasi Wisata Aik Rusa' Berehun ditunjukkan mulai dari gotong-royong dalam penyiapan lahan, pembangunan fasilitas, sampai perawatan fasilitas yang ada.

Saat ini telah dibangun 5 buah saung tempat makan dan istirahat 3 diantaranya berada di pinggir kolong bekas tambang timah agar lebih sejuk dan nyaman. Saung ini memiliki kegunaan multi fungsi, seperti untuk aktivitas makan bedulang, aktivitas berbagai paket wisata edukasi seperti belajar menganyam, melukis caping, bermain musik Gambus, aktivitas memancing ikan yang ada di dalam air danau, untuk pertemuan atau rapat komunitas dan lain sebagainya. Fasilitas penunjang lainnya yaitu 3 buah rumah payung untuk tempat bersantai, rumah apung Julong-julong, tempat cuci tangan, 1 buah mushola, homestay yang terletak di sekitar destinasi, 1 buah toilet, 1 buah tempat parkir, 1 buah kantin, 1 area tempat bermain anak dan 1 buah dapur masak. Fasilitas-fasilitas penunjang wisata di Destinasi Wisata Aik Rusa' Berehun secara keseluruhan memiliki kondisi yang baik dan dapat membuat wisatawan merasa nyaman dan dimudahkan. Adapun amenitas yang ada dapat dilihat pada gambar dibawah ini. 

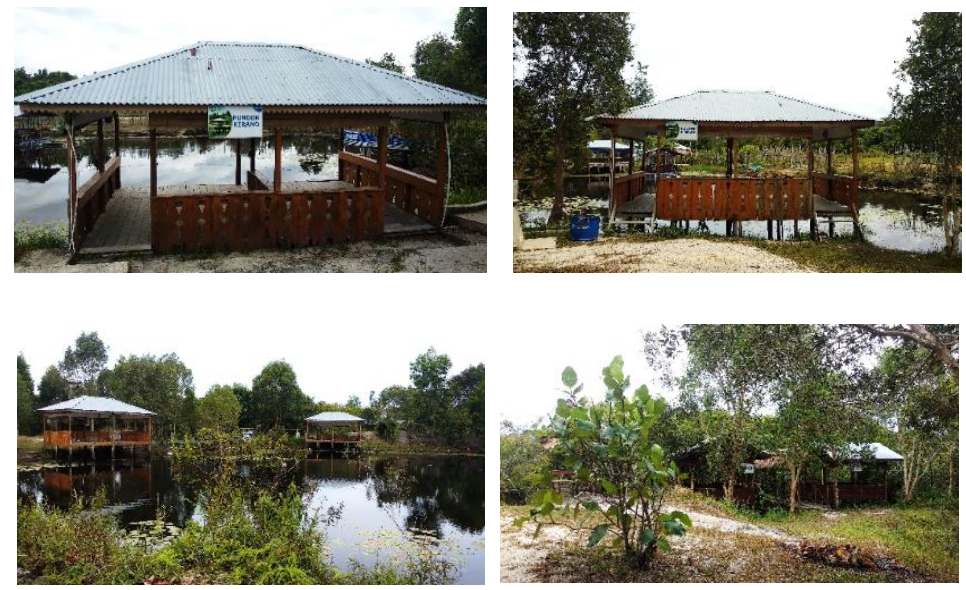

Gambar 5. Fasilitas Saung Tempat Wisatawan Beristirahat

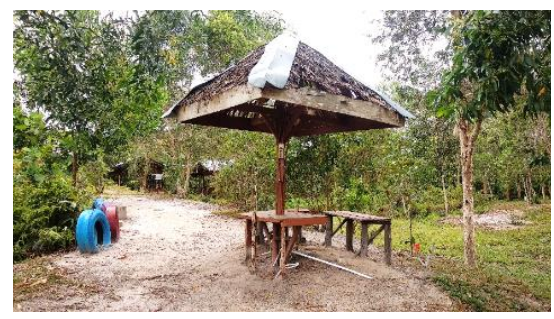

Gambar 6. Rumah Payung Tempat Wisatawan Bersantai
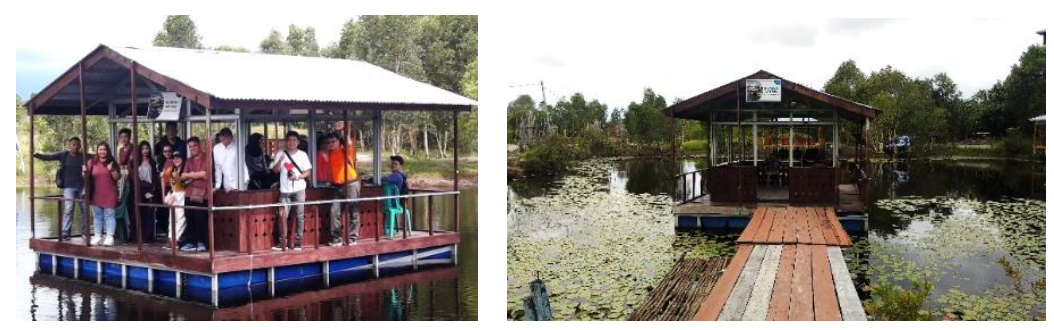

Gambar 7. Rumah Apung Julong-Julong
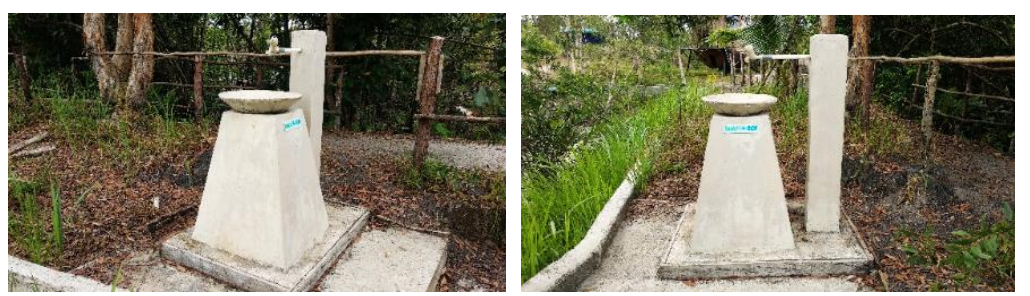

Gambar 8. Fasilitas Tempat Cuci Tangan

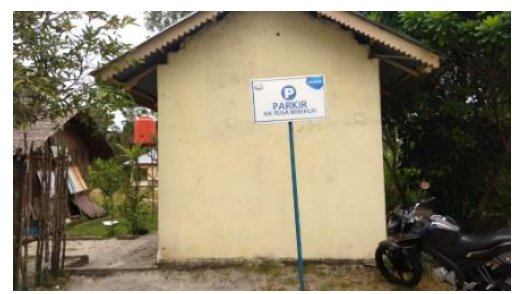

Gambar 9. Fasilitas Tempat Parkir 


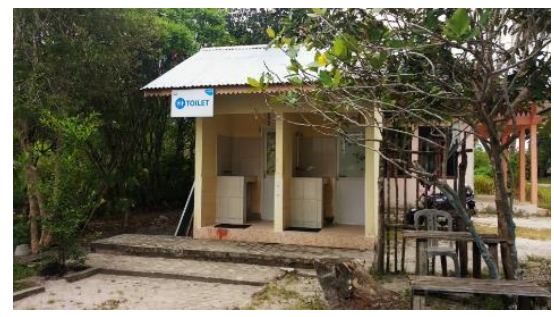

Gambar 10. Fasilitas Toilet

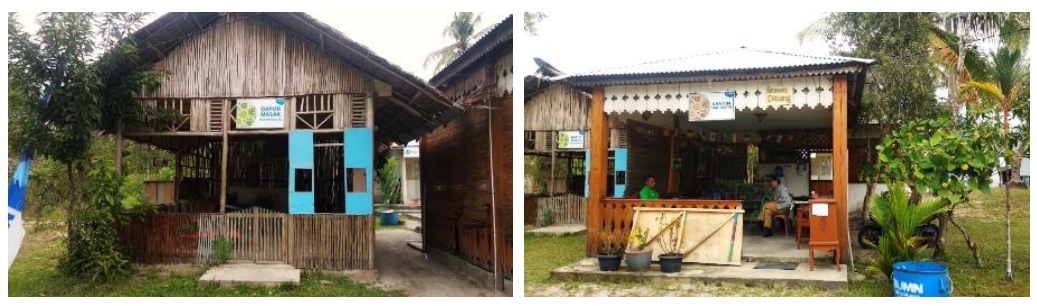

Gambar 11. Fasilitas Dapur Masak dan Kantin

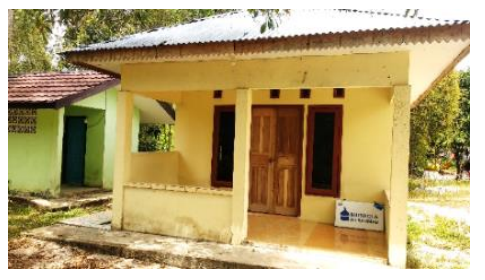

Gambar 12. Fasilitas Mushola

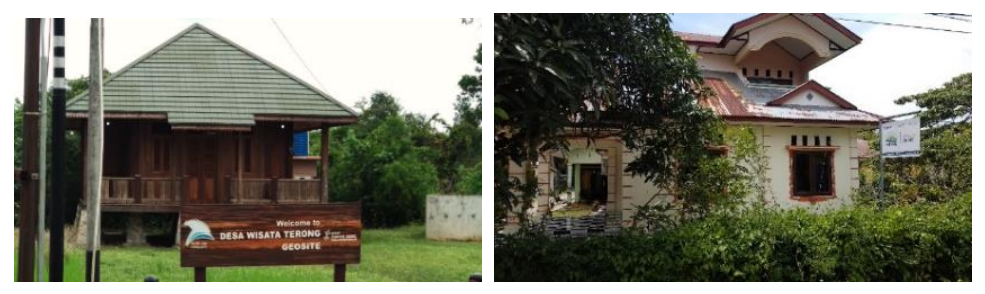

Gambar 13. Fasilitas Homestay

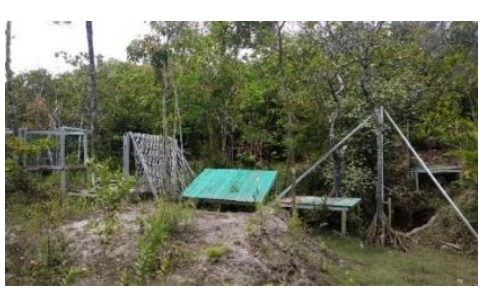

Gambar 14. Kondisi Fasilitas Tempat Bermain Anak yang Kurang Terawat di Destinasi Wisata Aik Rusa' Berehun

Kemudian untuk kondisi sarana dan prasarana khususnya fasilitas penunjang destinasi wisata Aik Rusa' Berehun perlu dilakukan penambahan dan peningkatan pada lampu penerangan jalan karena pada kondisi saat ini belum terdapat lampu penerangan sepanjang jalan dari jalan utama menuju destinasi wisata Aik Rusa' Berehun. Selain itu, pada fasilitas tempat bermain anak yang perlu dilakukan perbaikan dengan kondisi permainan yang lebih aman dan layak untuk anak bermain didalam area destinasi wisata Aik Rusa' Berehun. 
3. Identifikasi Accessibility (Aksesibilitas Wisata) Destinasi Wisata Aik Rusa' Berehun Aksesibilitas mencakup semua aspek yang memudahkan perjalanan wisatawan, serta sarana transportasi yang dapat membawa wisatawan dari titik keberangkatan ke titik tujuan wisata atau kembali lagi ke tempat asalnya ${ }^{[17]}$. Accessibility atau aksesibilitas meliputi akses jalan raya, ketersediaan sarana transportasi dan rambu-rambu penunjuk jalan agar wisatawan memperoleh pengalaman perjalanan yang mudah dan lancar.
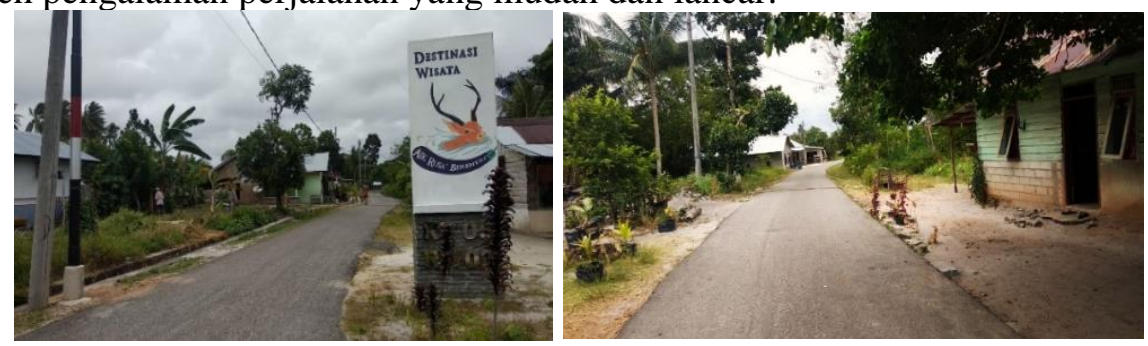

Gambar 15. Kondisi Aksesibilitas Menuju Destinasi Wisata Aik Rusa' Berehun dengan Kondisi Jalan Aspal yang Baik

Aksesibilitas menuju Destinasi Wisata Aik Rusa' Berehun dapat dikatakan sangat baik dan mudah dengan kondisi jalan aspal yang dapat dilalui oleh sepeda, sepeda motor, mobil, hingga bus yang mengangkut wisatawan menuju Destinasi Wisata Aik Rusa' Berehun. Namun, perlu adanya penambahan dan perbaikan kondisi aksesibilitas berupa perbaikan atau penambahan aspal pada jalan menuju Destinasi Wisata Aik Rusa' Berehun karena terdapat bagian jalan yang belum dibangun aspal sehingga kondisi permukaan jalan yang masih berpasir dan berbatu yang dapat membahayakan pengguna sepeda motor jika kondisi jalan setelah hujan yang cenderung licin.

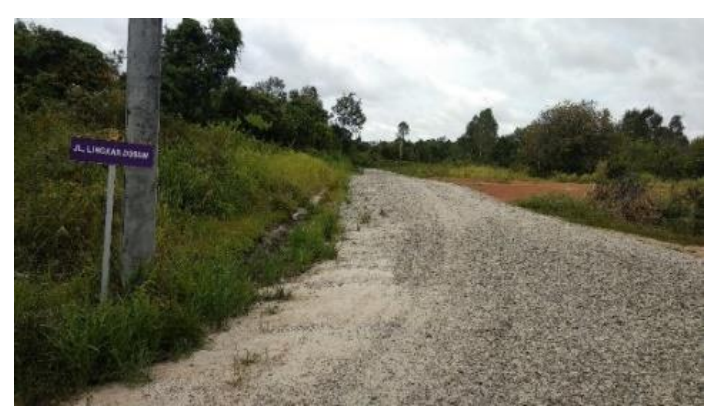

Gambar 16. Kondisi Bagian Jalan yang Perlu Dilakukan Perbaikan Menggunakan Aspal

\section{Identifikasi Ancilliary (Layanan Pendukung Wisata) Destinasi Wisata Aik Rusa'} Berehun

Ancilliary dapat diartikan sebagai adanya organisasi penyelenggara perjalanan wisatawan sehingga kegiatan wisata dapat dikontrol dan terus berjalan dengan baik. Aspek ini meliputi pemandu wisata, biro perjalanan, pemesanan tiket dan informasi destinasi ${ }^{[18]}$. Ancilliary berkaitan dengan adanya sebuah organisasi atau orang-orang yang bertugas mengurus destinasi wisata agar atraksi, aksesibilitas dan amenitas yang sudah ada tidak terbengkalai. Pengembangan destinasi wisata Aik Rusa' Berehun ini tidak terlepas dari peran masyarakat Desa Terong yang dalam perjalanannya membentuk Komunitas pengelola kawasan wisata Aik Rusa' Berehun ini. Komunitas ini dibentuk dan difasilitasi oleh Badan Permusyawaratan Desa Terong yang berkolaborasi dengan terbentuknya kesadaran masyarakat akan lingkungan dan wisata. Pemerintah desa bekerja sama dengan masyarakat lokal untuk menemukan cara pengelolaan kawasan kolong bekas tambang menjadi destinasi wisata baru yang dapat menarik wisatawan nusantara maupun wisatawan mancanegara.

Sehingga sebagai langkah awal pengelolaan kawasan kolong bekas tambang menjadi destinasi wisata, dibentuk kelompok masyarakat dengan tugas melakukan pengembangan dan pengelolaan destinasi wisata. Kelompok masyarakat ini beranggotakan 25 orang yang secara 
resmi terbentuk pada tanggal 20 April 2015 melalui Surat Keputusan Kepala Desa Teron. Kelompok masyarakat ini beranggotakan masyarakat yang memiliki kepedulian terhadap pelestarian lingkungan, kelompok ini bertugas mengelola destinasi wisata kolong bekas tambang yang sekaligus bertujuan melakukan penghijauan DAS Terong dengan berdasarkan prinsip gotong royong. Kelompok tersebut dinamakan Kelompok Masyarakat Aik Rusa' Berehun yang telah berhasil mengubah salah satu kolong bekas tambang timah di Kabupaten Belitung menjadi lebih bermanfaat sekaligus dapat meningkatkan kreatifitas masyarakat lokal Desa Terong.

Melalui hal ini juga diharapkan dapat mengubah bagaimana pola pikir masyarakat agar mulai membuka diri dan menyesuaikan untuk pembangunan destinasi wisata sebagai penunjang perekonomian baru bagi masyarakat lokal. Sehingga dalam berjalannya kegiatan wisata di destinasi wisata ini telah dikelola oleh kelompok masyarakat Aik Rusa' Berehun dengan tetap berkomunikasi dan tetap berkoordinasi dengan pemerintah. Kemudian untuk ketersediaan informasi tentang destinasi telah tersedia pada website dan media sosial lainnya yang dikelola langsung oleh kelompok masyarakat Aik Rusa' Berehun.

\section{Analisis dan Pembahasan Konektivitas Destinasi Wisata Desa Terong dengan Destinasi Wisata Sekitar}

Berdasarkan Peraturan Pemerintah Republik Indonesia Nomor 50 Tahun 2011 Tentang Rencana Induk Pembangunan Kepariwisataan Nasional Tahun 2010-2025 Desa Terong terletak pada cluster KSPN Tanjung Kelayang dan sekitarnya. Semenjak ditetapkan Tanjung Kelayang dan sekitarnya sebagai KSPN, Pemerintah Pusat bersama Pemerintah Daerah berusaha mempromosikan Tanjung Kelayang sebagai destinasi wisata utama. Hal ini menyebabkan wisatawan nusantara maupun mancanegara telah mengenal akrab bahwa destinasi wisata di Kabupaten Belitung yaitu identik dengan keindahan alam pantai. Sehingga destinasi wisata utama yang dikunjungi oleh wisatawan ketika mengunjungi Kabupaten Belitung yaitu destinasi wisata Pantai khususnya kawasan Pantai Tanjung Kelayang dan Pantai Tanjung Tinggi.

Desa Terong berdasarkan kebijakan KSPN termasuk ke dalam kawasan sekitar Tanjung Kelayang sehingga dalam pengembangan infrastruktur juga termasuk ke dalam salah satu prioritas Kawasan Pariwisata Nasional dari seluruh Indonesia. Dalam beberapa travel yang menyediakan paket berwisata khususnya di Kabupaten Belitung telah mengelompokkan destinasi wisata Tanjung Kelayang, Tanjung Tinggi, dan Desa Terong berada dalam satu kelompok destinasi. Hal ini dikarenakan Desa Terong memiliki lokasi yang sangat strategis di jalur perlintasan pantai utara Pulau Belitung dan jalur lintasan pariwisata Tanjung PandanTanjung Kelayang-Tanjung Tinggi. Adanya pengembangan kolong bekas tambang menjadi destinasi wisata Aik Rusa' Berehun di Desa Terong kini berfungsi sebagai destinasi wisata pendukung bagi Tanjung Kelayang dan Tanjung Tinggi serta sebagai alternatif jalur wisata baru bagi wisatawan untuk beristirahat ataupun mencari destinasi wisata yang tetap menarik walaupun bukan berupa atraksi wisata alam pantai. 


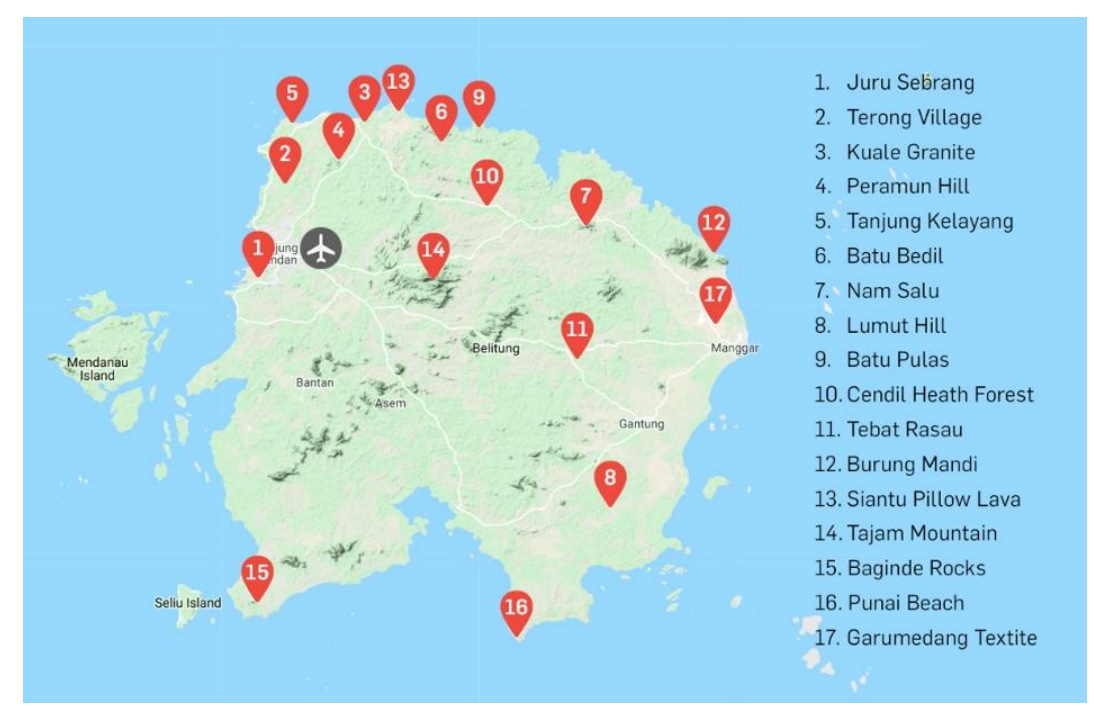

Gambar 17. Peta Sebaran Geosite Belitong Global Geopark

Gambar di atas merupakan peta sebaran Geosite dari Belitong Global Geopark. Pada tahun 2021 UNESCO telah menetapkan Desa Terong sebagai salah satu Geosite yang juga terintegrasi dengan Geosite lainnya di dalam Belitong Global Geopark. Di dalam Desa Terong memiliki potensi kolaborasi dari beberapa komunitas ataupun kelompok masyarakat dalam mengelola destinasi wisata di dalamnya. Sehingga dengan ditetapkannya menjadi salah satu geosite, diharapkan Desa Terong khususnya Destinasi Wisata Aik Rusa' Berehun dapat lebih dikenal oleh wisatawan dan berkembang menjadi salah satu destinasi wisata ikonik di Kabupaten Belitung. Adapun peta sebaran destinasi wisata yang berada di sekitar Desa Terong dapat dilihat pada gambar berikut.

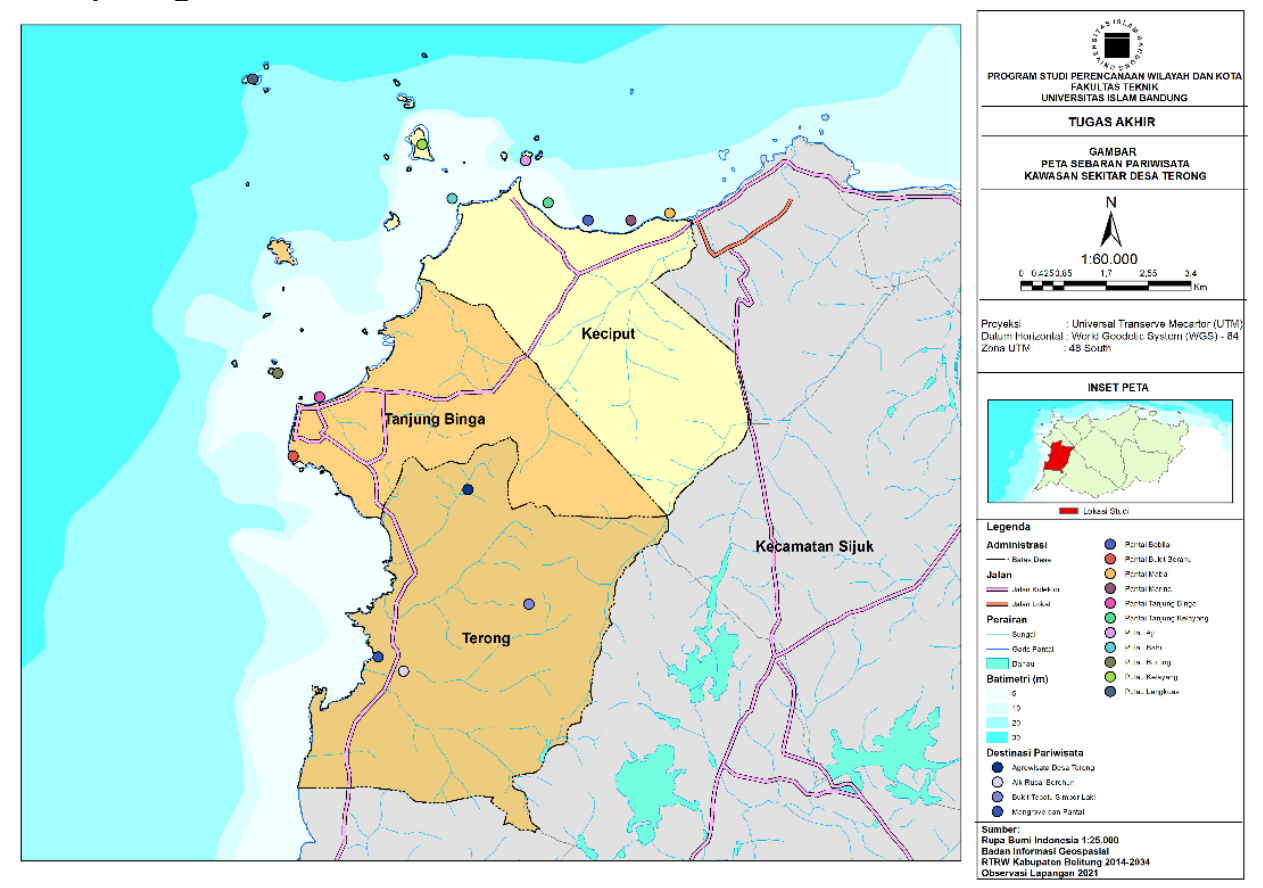

Gambar 18. Peta Sebaran Destinasi Wisata di Sekitar Desa Terong 


\section{Kesimpulan} berikut:

Dari pembahasan yang telah djabarkan, dapat ditarik beberapa kesimpulan yaitu sebagai

1. Pengembangan kolong bekas tambang menjadi Destinasi Wisata Aik Rusa' Berehun di Desa Terong telah berhasil beroperasi untuk kunjungan berwisata selama 5 tahun. Selama itu pula pengembangan komponen penunjang wisata 4A di destinasi wisata tersebut terus menerus dilakukan peningkatan, pengelolaan dan pengembangan agar terjadi keberlanjutan suatu kegiatan wisata di dalamnya. Perkembangan Destinasi Wisata Aik Rusa' Berehun sudah baik di dalam konten maupun isi untuk didatangi wisatawan. Komponen 4A yang tersedia sudah bisa digunakan untuk mengakomodir wisatawan dengan baik sehingga wisatawan yang berkunjung dapat merasa nyaman dan menikmati objek wisata yang ada meskipun di beberapa aspek masih butuh pembenahan.

2. Attraction yang ada di destinasi wisata Aik Rusa' Berehun merupakan daya tarik wisata alam yaitu berupa kolong bekas tambang yang diubah menjadi objek wisata, atraksi lainnya yaitu berupa atraksi pertunjukan kebudayaan lokal, selain itu pengunjung bisa memiliki pengalaman berwisata edukasi mengenai cara memasak makanan lokal sekaligus menikmati kuliner khas Desa Terong, wisata edukasi lainnya juga berkaitan dengan pembuatan kerajinan khas Desa Terong serta wisata edukasi belajar kesenian tari dan alat musik gambus.

3. Amenities yang ada di destinasi wisata Aik Rusa' Berehun dapat dikatakan sudah lengkap mulai dari homestay, sarana dan prasarana maupun fasilitas-fasilitas penunjang kegiatan wisata lainnya sudah tersedia dengan baik. Amenities yang ada dapat dengan baik menunjang segala kegiatan para wisatawan di dalamnya dan memberikan kesan aman dan nyaman bagi wisatawan. Walaupun masih perlu dilakukan peningkatan pada fasilitas taman bermain anak agar tetap menarik karena saat ini sudah mulai mengalami beberapa kerusakan.

4. Accessibility menuju destinasi wisata Aik Rusa' Berehun tergolong baik dengan jangkauan menuju lokasi objek wisata yang sangat mudah dan aman. Kondisi jalan yang sudah dilakukan pengaspalan membuat akses menuju lokasi objek menjadi sangat mudah terjangkau. Kapasitas jalan dapat dengan mudah dilalui oleh kendaraan roda dua sampai dengan roda empat.

5. Ancilliary services yang ada di Destinasi Wisata Aik Rusa' Berehun berkaitan dengan ketersediaan organisasi pengelola destinasi yaitu dilakukan oleh Kelompok Masyarakat Aik Rusa' Berehun dengan tetap berkomunikasi dan tetap berkoordinasi dengan pemerintah. Kemudian untuk ketersediaan informasi tentang destinasi telah tersedia pada website dan media sosial lainnya yang dikelola langsung oleh kelompok masyarakat Aik Rusa' Berehun.

6. Konektivitas dengan destinasi wisata sekitar telah diidentifikasi bahwa keberadaan destinasi wisata Aik Rusa' Berehun sebagai sebuah destinasi wisata baru di Desa Terong sekaligus berfungsi sebagai destinasi wisata pendukung bagi Tanjung Kelayang dan Tanjung Tinggi serta sebagai alternatif jalur wisata baru bagi wisatawan untuk beristirahat ataupun mencari destinasi wisata yang tetap menarik walaupun bukan berupa atraksi wisata alam pantai.

\section{Acknowledge}

Secara khusus penulis ingin mengucapkan terima kasih kepada seluruh staf pengajar dan karyawan Program Studi PWK Universitas Islam Bandung atas ilmu, bimbingan dan bantuannya. Ucapan terima kasih juga penulis sampaikan kepada kedua orang tua, kakak-kakak penulis, teman-teman, serta sahabat yang terus memberikan bantuan dan dukungan. Kemudian kepada instansi Dinas Pariwisata Kabupaten Belitung, Pemerintah Desa Terong, Kelompok Masyarakat Aik Rusa' Berehun, dan semua masyarakat dan pelaku usaha kepariwisataan yang telah menjadi informan dan memberikan data dalam penelitian ini penulis ucapkan terima kasih yang sebesar-besarnya. 


\section{Daftar Pustaka}

[1] Widyastuti, H., Marsoyo, A., \& Setiawan, B. (2019). Analisis Konektivitas Antar Destinasi Pariwisata Pantai di Daerah Istimewa Yogyakarta. Region, 14(1), 1-12.

[2] Rizkiyani, A. H., \& Suprihardjo, R. (2013). Pengembangan Kawasan Wisata Pesisir Talang Siring Di Kabupaten Pamekasan. Jurnal Teknik Pomits, 2(2), C215-C220.

[3] Astuti, N. N. S., Ginaya, G., \& Susyarini, N. P. W. A. (2019). Designing Bali Tourism Model Through The Implementation Of Tri Hita Karana And Sad Kertih Values. International Journal Of Linguistics, Literature And Culture, 5(1), 12-23. Https://doi.org/10.21744/Ijllc.V5n1.461

[4] Irvani, \& Artasari, E. D. (2018). Studi Karakteristik Tailing Pada Lokasi Eks Penambangan Timah di Bukit Sambung Giri Kecamatan Merawang Kabupaten Bangka. Promine Journal, 6(2), 31-36. https://doi.org/10.33019/promine.v6i2.1086

[5] Meyzilia, A. (2018). Pemanfaatan Air Kolong Bekas Tambang Timah Sebagai Penambah Sumber Air Tanah Menggunakan Lubang Kompos Di Bangka Belitung. Jurnal Pendidikan Ilmu Sosial, 27(1), 22-30.

[6] Sabri, F., \& Wijayanto, R. (2019). Kajian Pemanfaatan Potensi Kulong Di Kabupaten Bangka Tengah. Jurnal Fropil, 7(2), 85-99. https://doi.org/10.33019/fropil.v7i2.1626

[7] Salmon, I. P. P., I, I., Pujianto, W. E., \& Nadyah, F. (2020). Embrio Destinasi Wisata Religi Baru: Identifikasi Komponen 3A Berbasis Wisata Ziarah Desa Balun, Lamongan. Jurnal Ilmiah Syi'ar, 20(1), 33. https://doi.org/10.29300/syr.v20i1.2948

[8] Prabawati, N. P. D. (2020). Desa Canggu, Bali Sebuah Basecamp Bagi Digital Nomad? Identifikasi Produk Wisata Berdasarkan 4 A (Attraction, Amenity, Accessibility, Ancilliary). Jurnal Kepariwisataan Indonesia: Jurnal Penelitian Dan Pengembangan Kepariwisataan Indonesia, 14(2), 91-108. https://doi.org/10.47608/jki.v14i22020.91108

[12] Wirartha, I Made (2006). Metode Penelitian Sosial Ekonomi. Yogyakarta: Andi Offset

[13] Chaerunissa, S. F., \& Yuniningsih, T. (2020). Analisis Komponen Pengembangan Pariwisata Desa Wisata Wonolopo Kota Semarang. Journal of Public Policy and Management Review, 9(4), 17. https://doi.org/10.14710/jppmr.v9i4.28998

[14] Utama, I. G. B. R. (2017). Pemasaran Pariwisata. Penerbit Andi.

[16] Zaenuri, M. (2012). Perencanaan Strategis Kepariwisataan Daerah Konsep dan Aplikasi. E-Gov Publishing (1st Ed., Vol. 1)

[17] Isdarmanto. (2016). Dasar-Dasar Kepariwisataan Dan Pengelolaan Destinasi Pariwisata (1st Ed.). Penerbit Gerbang Media Aksara Dan Stipram Yogyakarta 